\title{
Entrevista com Eunice Ostrensky
}

\section{Por Leandro de Pádua Rodrigues \& Patrick Silva}

Eunice Ostrensky possui graduação, mestrado e doutorado em Filosofia pela Universidade de São Paulo (1993, 1997 e 2002, respectivamente). É professora doutora no Departamento de Ciência Política da mesma universidade desde 2007. Também é coordenadora da Comissão de Graduação do Departamento para o curso de Ciências Sociais. Atua nas áreas de Filosofia Política e Teoria Política.

Primeiros Estudos: O que motivou você a escolher o curso de Filosofia na graduação?

EUNICE OSTRENSKY: Não houve uma motivação mais elevada. Eu fazia Economia na Faculdade de Economia e Administração (FEA), mas sentia que o curso era incompatível comigo. Ao mesmo tempo, eu tinha um grande interesse pelos cursos de Humanas e também por biologia. Como eu sempre gostei de ler e escrever, decidi investir nas Humanas. 0 meu preferido era o curso de Letras, depois vinham História, Ciências Sociais e, por último, Filosofia. Eu decidi assistir aulas desses cursos e notei que o mais organizado era o de Filosofia. Além disso, havia algumas perguntas e curiosidades que eu ansiava por responder. No curso de Filosofia, eu acreditava que conseguiria respondê-las. Eu tinha uma visão muito pessimista sobre o gênero humano, por exemplo, e achava que a filosofia me daria uma visão mais favorável do homem no exercício daquilo que ele possui de mais elevado. Eu tinha essa ambição.

PRIMEIRos Estudos: Em sua opinião, você conseguiu realizar tal ambição?

EUNICE OSTRENSKY: É difícil responder. Na medida em que estudamos, temos acesso a coisas não apenas elevadas, mas, às vezes, até brutais. Na Filosofia não é diferente. Ao longo do curso nós acabamos por perder a ingenuidade com o nosso objeto de estudo. Isso acontece com uma parte dos alunos do curso de Ciências 
Sociais. Eles entram no curso, acham que irão ser uma coisa e o terminam sem saber ao certo [se] se tornarão. Então, ao longo do curso, ocorre um processo de amadurecimento que contribui para a perda da ingenuidade, fato que nos auxilia na realização (ou não) das nossas ambições iniciais. De fato, eu acho que não alcancei minhas ambições, mas, de certa forma, elas deixaram de ter sentido para mim. Se meu caso serve de exemplo de outros, posso dizer que os alunos que se formam são muito diferentes dos alunos no começo do curso. É como se eles sofressem um rito de passagem.

\section{Primeiros Estudos: Como era o curso de Filosofia quando você era estudante?}

EuniCE OSTRENSKY: Quando eu fiz filosofia, o número de ingressantes era menor do que hoje. Mas, ao mesmo tempo, formavam-se dois por ano. Ou seja, existia uma evasão escolar incrível. Além disso, era um curso muito difícil: exigia muita carga de leitura, não tinha aula todos os dias (no máximo três vezes por semana - e os restantes dos dias eram estudos em casa).

\section{Primeiros Estudos: Como você decidiu estudar Thomas Hobbes?}

EUNICE OSTRENSKY: É uma história engraçada. Eu nunca tinha estudado Filosofia até então. Antes de parar na Filosofia, eu circulei um pouco por alguns lugares. Cursei jornalismo durante um ano na PUC e havia uma disciplina de Filosofia, na qual nós só tínhamos que ler aquelas introduções da Coleção Os Pensadores. Ou seja, era um curso péssimo e por isso eu não tinha ideia do que era Filosofia. Quando entrei na Universidade de São Paulo (USP), na minha primeira aula, me deparei com uma série de textos em latim e francês. Uma discussão extremamente abstrata. A minha primeira aula foi sobre Descartes e eu não entendi absolutamente nada. Posso dizer que no primeiro semestre essa situação permaneceu. No segundo semestre eu tive uma disciplina de oito créditos chamada Filosofia Geral, ministrada por dois professores. Um deles ensinava Kant e eu literalmente não entendia nada. 0 outro professor ministrava Filosofia Política em um curso que estudávamos Hobbes, Locke e Rousseau. Quando eu comecei a estudar Hobbes, finalmente algo começou a fazer sentido para mim: dei-me conta que era capaz de entender seus textos (ao 
contrário de Kant e do meu primeiro semestre). Foi uma luz no meu caminho. Daí comecei a explorar melhor o tema. Além disso, eu achava que estudando Hobbes eu seria capaz de responder a uma série de dúvidas que tinha. No entanto, ao longo do curso passei a gostar de três grandes áreas da Filosofia: Filosofia Política, Estética e Filosofia Moderna. Acabei escolhendo a primeira.

Primeiros Estudos: Por que essa opção?

EUNICE OSTRENSKY: Foi um pouco aleatório. Nós fazemos escolhas ao longo da graduação que não são completamente pensadas de tal forma que possamos ver todas as suas consequências. Primeiramente, eu gostava da área. Embora gostasse muito de Estética também, a minha formação na Filosofia foi mais na área de Filosofia Moderna. Como eu queria fazer uma iniciação científica e também como tive um bom desempenho estudando Hobbes, acabei optando pela área de Filosofia Política. Nesse processo há outra coisa engraçada. Quando fui procurar o professor para pedir orientação de iniciação científica, ele me perguntou o que eu queria estudar e eu respondi que não sabia, que queria estudar Filosofia. Ele respondeu para eu retornar quando tivesse uma ideia mais clara.

PRIMEIRos EsTUdos: Você retornou com essa ideia mais clara?

EUNICE OSTRENSKY: Não, porque me dei conta que não tinha nenhuma ideia clara ainda. Mas, no ano seguinte, a Professora Maria das Graças Souza (minha orientadora de iniciação científica) criou um grupo de estudos para estudar Filosofia Política Moderna e comecei a participar dele. Ao mesmo tempo, inicie a minha pesquisa de graduação. Pedi uma bolsa à Fundação de Amparo à Pesquisa do Estado de São Paulo (FAPESP), coisa que quase ninguém fazia. Na verdade, bolsa de iniciação científica era algo raro, porque primeiro não tinha muitos alunos: para vocês terem uma ideia, na época uma disciplina muito frequentada possuía no máximo 20 alunos. Eram muito comum cursos com apenas três ou cinco alunos.

Primeiros Estudos: Qual tema especificamente você estudou na iniciação cientifica? 
EUNICE OSTRENSKY: Nunca gostei muito de ficar presa a apenas uma obra do autor. Eu investiguei um problema da teoria de Hobbes em três obras diferentes. Na filosofia há uma preocupação muito grande em encontrar sistemas nos textos clássicos. 0 filósofo que não possuísse um sistema no interior de seus textos não poderia ser considerado como tal. Então, eu queria demonstrar que Hobbes, um filósofo considerado altamente sistemático, havia modificado posições políticas importantes nas suas obras. Foi assim que eu comecei a me sentir atraída pelos contextos nos quais os textos eram publicados.

Primeiros Estudos: Foi assim que você começou a se aproximar da historiografia de Cambridge?

Eunice OSTREnSKy: Sim. Primeiro eu li aquele livro pequeno do Skinner ${ }^{1}$ sobre o Maquiavel (SKINNER, 1981). Depois, li As fundações do pensamento político moderno (SKINNER, 1996). Essas leituras foram extremamente esclarecedoras, pois comecei a achar que estava entendendo alguma coisa. Por isso, comecei a pensar que tinha que seguir esse caminho. Há outro elemento importante também. Na época em que eu estudei Filosofia, a bibliografia estrangeira era dominante: nem livros dos próprios filósofos e nem de seus comentadores eram encontrados em português. Então, os alunos eram levados a estudar um filósofo (ou tema), cujo idioma estrangeiro lhes fosse familiar.

Primeiros Estudos: Mas já na sua graduação você teve contatos com os livros de Quentin Skinner e J. G. A. Pocock?

EuniCE OSTRENSKY: Não. Na época em que fiz graduação os textos e livros que esses autores produziam não eram muito lidos na Faculdade. Hoje ainda existe alguma ressalva em relação a essa bibliografia. Mas os meus estudos sobre método voltados para a historiografia de Cambridge ocorreram em um momento mais tardio e não na graduação.

\footnotetext{
${ }^{1}$ Quentin Skinner ocupa a cátedra Barber Beaumont de Humanidades na Queen Mary, Universidade de Londres. Foi titular da Cadeira de História Moderna da Universidade de Cambridge, onde lecionou por muitos anos no Christ's College. É apontado, junto com John Dunn e J. G. A. Pocock, como fundador da Escola de Cambridge de Historia do Pensamento Político.
} 
Primeiros Estudos: E você comentou que queria ter feito o mestrado na Letras para estudar literatura russa. Por que não fez?

EUNICE OSTRENSKY: Quando eu saí da graduação, embora estivesse aberta a possibilidade de estudar russo, eu precisava rapidamente de uma bolsa. Eu continuava a dar aula de português para estrangeiros, fazia traduções de manuais de ética para empresas, morava em uma republica e precisava pagar o aluguel. 0 chefe do Departamento de Filosofia na época me disse que eu tinha terminado bem a iniciação científica e que podia transformar a conclusão da minha iniciação cintífica em um projeto de mestrado. Além disso, eu passaria a receber a bolsa de mestrado logo após a conclusão do processo de seleção. Eu pensei e decidi fazer o processo de seleção. Mais uma vez, eu fui levada pelas contingências. O processo de seleção era bem diferente do daqui (DCP/USP): só havia uma prova de línguas, que exigia a tradução de um pequeno texto, e uma entrevista. Como fui aprovada e o professor Renato Janine ${ }^{2}$ se dispôs a me orientar, comecei a fazer o Mestrado.

\section{Primeiros Estudos: E sobre o seu doutorado, você não cogitou fazê-lo na Letras?}

EUNICE OSTRENSKY: Quando eu fiz o mestrado já havia essa transição do mestrado e do doutorado, para um mestrado mais curto, mais direto. Eu fiz o mestrado em três anos e meio, mas podia fazer em até quatro anos. Já era uma diferença considerável aos mestrados que haviam antecedido o meu. Sei de gente que levou dez anos para concluir o mestrado ou quinze anos para concluir o doutorado. E as poucas pessoas que tinham bolsa recebiam por até cinco, seis anos. Então, durante o mestrado de alguma maneira eu já estava explorando o que eu faria no doutorado e não pensava mais em mudar meu objeto de estudo. Em certo momento do mestrado lancei uma pergunta que exigiria um estudo grande, de cerca de quatro anos - e foi difícil responder nesse prazo, se é que eu consegui responder. Assim, já antes de defender a dissertação, entrei com pedido para a FAPESP de uma bolsa para o doutorado e antes mesmo de ingressar no doutorado minha bolsa foi aprovada.

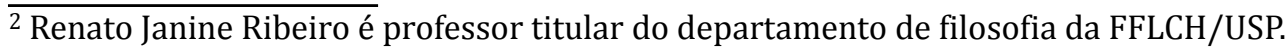


Primeiros Estudos: Você saiu do país no doutorado. Como foi a experiência?

EUNICE OSTRENSKY: Para poder estudar na Inglaterra, que há muito tempo é um país caro, eu economizei toda a verba da reserva técnica disponibilizada pela FAPESP para os meus três primeiros anos de doutorado. Em Londres, não fiquei vinculada formalmente a nenhuma instituição. Pesquisei fontes primárias (jornais, atas do Parlamento, panfletos) na Biblioteca britânica. Mas, informalmente, mantive um vínculo com Quentin Skinner. Participei de eventos nas Universidades de Cambridge e Londres, mas para mim, que queria ler toda aquela bibliografia marginal, fazia mais sentido explorar a seção de livros raros da Biblioteca do que participar de cursos. Foi uma experiência decisiva que eu recomendo. Cultural e intelectualmente, é um momento importante.

PRIMEIRos Estudos: Você fez contato com o Skinner antes de ir ou apenas quando chegou à Inglaterra?

Eunice OSTRENSKY: No ano anterior eu fui para a Europa e, antes de viajar, escrevi para o Skinner, dizendo que gostaria muito de conhecê-lo. Foi muito atrevimento de minha parte, porque, em geral, sou relativamente tímida. Mas ele respondeu, convidando-me para ir almoçarmos no Christ's College ${ }^{3}$. Skinner é uma das pessoas mais gentis e generosas que conheço. Naquela tarde de 2000, depois do almoço, ele me levou até a biblioteca da universidade, indicou os livros que eu tinha de ler. Ele me orientou, em suma. No ano seguinte, já durante o "sanduíche", eu fui para Biblioteca Britânica sabendo o que tinha que ler e onde estava o que eu teria de investigar. Naquele ano se comemorava o aniversário dos 350 anos do Leviatã e Skinner me convidou para o ciclo de conferências relativo a essa data. Depois que voltei para o Brasil, nós trocamos cartas, e eu o convidei várias vezes para vir ao Brasil - e várias vezes ele disse que viria. Mas virá em outubro do ano que vem, finalmente! Também tive contato com muitos outros professores. Circulei bastante por lá, foi realmente uma experiência importante, porque me permitiu trilhar um

\footnotetext{
$\overline{3}$ College é a forma como são chamadas as diversas unidades de ensino de cada Universidade nos países anglo-saxões. Fundado em 1437, o Christ's College é uma das unidades mais antigas da Universidade de Cambridge, e a de reputação mais alta.
} 
caminho novo no doutorado. Foi a partir disso que finalmente eu consegui responder a questão que me tinha surgido ainda no mestrado.

\section{PRIMEIRos Estudos: E qual era essa questão?}

Eunice OSTRENSKY: A minha questão surgiu das traduções que eu tinha feito. 0 primeiro livro que traduzi, acho que foi em 1999, Da liberdade/Utilitarismo, de J. Stuart Mill. Eu já havia trabalhado como revisora dos Dois Tratados, de John Locke, e A teoria dos sentimentos morais, de Adam Smith. Depois eu traduzi o Behemoth, de Hobbes, que fazia parte do meu mestrado. Não a tradução, mas o livro. E nesse livro a todo momento Hobbes se refere a uma porção de grupos políticos e os trata como se eles fossem irracionais, uns loucos. Hobbes era muito gentil ao tratar os seus adversários [Risos]. Eu pensei: "já conheço a crítica de Hobbes a seus adversários políticos, agora a questão é saber o que dizem esses adversários". A pergunta que eu então formulei era a seguinte: “Que discursos Hobbes está atacando?”. Mas essa era uma pergunta muito difícil de ser respondida, porque os vários discursos atacados não são necessariamente coerentes, sistemáticos ou mesmo filosóficos. Foi isso o que me motivou a estudar no doutorado os opositores do Hobbes, muitos dos quais, porém, talvez nem soubessem que Hobbes havia escrito contra eles.

Primeiros Estudos: Você começou um pós-doutorado que foi interrompido. As pesquisas, atualmente, estão mais relacionadas ao doutorado ou a esse pósdoutorado?

EUNICE OSTRENSKY: Na verdade eu estou concluindo, espero concluir até o final do ano, uma pesquisa que é uma espécie de apêndice do meu doutorado, embora ela vá ficar tão grande quanto o doutorado. É o último respiro do doutorado, embora sejam abordadas algumas questões diferentes, mas é quase o mesmo período, os mesmo autores, mas o enfoque se faz sobre diferentes experimentos constitucionais pensados por teóricos e outros autores políticos. 0 meu doutorado foi até 1649 , acabou com a execução do Rei ${ }^{4}$. A pesquisa de pós- doutorado acabou ficando um pouco parada, porque depois de defender o doutorado eu tive filhas, fiz algumas traduções, dei aulas em instituições privadas, além de fazer concursos.

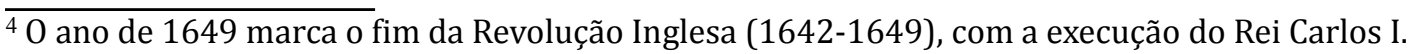


Acho que tem um momento em que nós precisamos parar para trabalhar mesmo. Interromper a pesquisa, reciclar-se e dar aula é uma boa oportunidade para pensar novos temas de estudo, e no meu caso os temas de pesquisa não me permitiam pensar além deles. Por outro lado, é muito difícil continuar pesquisando quando nós começamos a dar aula. As aulas tomam muito tempo, tanto para serem preparadas, como para serem ministradas. Aliás, é um desgaste físico muito grande dar aula. Sobre a minha atual pesquisa, como eu disse, espero terminá-la no final deste ano. Depois sairá um livro, ainda não sei bem ao certo como, mas tem uma série de artigos que eu preciso organizar. Depois disso, vou pular o século XVIII e vou mudar minha pesquisa para a França, ou seja, vou mudar totalmente meu objeto de pesquisa, mas ainda não sei exatamente como. Eu conto fazer um novo pós-doutorado e, para tal, quero conseguir pensar sobre a pesquisa, pois desde que terminei o doutorado não consegui pensar sobre isso.

Primeiros Estudos: $E$ as suas pesquisas se mantiveram na linha da Escola de Cambridge ${ }^{5}$ ? Você está pensando em agregar outros métodos?

Eunice OSTRENSKY: Sim. Não estou convencida que devo mudar o método de análise. Talvez no futuro eu mude, mas por enquanto não. Acho que para estudar a Inglaterra é preciso um método inglês [risos]. Talvez na França o método deva ser francês. Preciso dizer, porém, que gosto muito desse método [da Escola de Cambridge], pois ele responde uma série de questões minhas. Agora estou lendo um autor, historiador, que é o Robert Darnton ${ }^{6}$, que investiga textos que não são filosóficos, que não são políticos. Um dos capítulos do livro, chamado o grande massacre dos gatos, procura extrair dos contos de fadas como seria a vida social dos camponeses franceses, os camponeses de quem [Karl] Marx fala no 18 Brumário [de Luis Bonaparte, 1851]. Eu gosto muito desse tipo de coisa. Meu

\footnotetext{
${ }^{5}$ Genericamente, a escola da Historiografia de Cambridge destaca a importância de se estudar um escrito político tendo em vista tanto o contexto histórico, no qual o autor (geralmente político) estava inserido, bem como o contexto linguístico que lhe estava disponível, limitando o escopo do significado de certas palavras e conceitos. Assim, por exemplo, Maquiavel, ao mencionar o vocábulo "Estado" em seus escritos, não se referia a um aparato burocrático detentor do monopólio legítimo da força. Dentre os grandes historiadores de tal escola, é possível citar John Dunn, J. G. A. Pocock e Quentin Skinner, entre os quais existem algumas divergências com relação ao uso do método contextualista.

${ }^{6}$ Robert Darnton é um historiador americano especializado na França do século XVIII.
} 
interesse não é só estudar o que [falam] os grandes autores das teorias já institucionalizadas, mas também aquilo que embasa esses textos. Para ficar no exemplo francês, não só estudar o que falou o Rousseau, mas o que falou um jacobino que leu Rousseau. Ele está lendo o Rousseau e, às vezes, sente que é o próprio Rousseau, tem a ideia de que está reproduzindo Rousseau ao ser um jacobino. Mas seria então Rousseau um jacobino? As pessoas invertem completamente as setas. Muitas das questões que penso em abordar apareceram quando estava me preparando para dar o curso de Política III,[matéria obrigatória no currículo do curso de Ciências Sociais e que tem como eixo temático Teoria Política Moderna]. Como tive de estudar para dar o curso, acabei me dedicando mais profundamente a Montesquieu e me deparei com questões interessantíssimas, que nunca tinha pensado.

Primeiros Estudos: Nós vemos diferenças muito grandes entre os departamentos com relação ao tipo de abordagem com as disciplinas obrigatórias. O DCP faz uma introdução sobre as três áreas em Política I, depois um ano de Teoria Política [Política II e Política III] e, depois, um semestre na área de Instituições. Não há linearidade, o que causa um estranhamento entre os alunos.

EUNICE OSTRENSKY: [Interrompe a pergunta] É mesmo?

Primeiros Estudos: Sim, é verdade. Há também uma queixa, que diz respeito à carga de leitura, principalmente nos semestres de Teoria Política. Muita literatura e a aula sobre capítulos específicos dessas obras indicadas. Contudo, nós acreditamos que exista uma razão de se fazer isso. O que se pretende?

EUNICE OSTRENSKY: Há um debate dentro do DCP que diz respeito à forma como vamos tratar os clássicos dentro das matérias obrigatórias. Ao longo dos anos, rearranjos nas disciplinas de Política I e II impediram, não sei exatamente por qual razão, que Política II ocupasse o lugar de Política I. E agora é muito difícil mudar. Porque teríamos que ter dois cursos ao mesmo tempo para contemplar os ingressantes e os ingressantes posteriores. Há ainda o problema da falta de professores de teoria. Mas infelizmente vai continuar assim por algum tempo. 
Com relação à carga de leitura e qual perfil de aluno se espera, eu posso falar por mim e não por nenhum dos meus colegas, como ministrante da disciplina. Eu não espero que os alunos leiam tudo. Eu sempre recorto as leituras, sugiro o que que ler e o que não ler. E isso é importante de ser feito. É irreal esperar do aluno que ele vá ler tudo, e se ele lê muito, com certeza não entenderá tudo. Mas é uma leitura muito interessante. Vale a pena! [risos]. 0 recorte tem que ser feito pelo professor. $\mathrm{O}$ aluno não tem condições de fazer isso. Mas mesmo assim a carga de leitura continua elevada, a bibliografia é mais densa, pois os cursos de teoria de fato são mais filosóficos. Cinquenta páginas de teoria não equivalem a 50 páginas de uma obra que foi escrita há dois anos. A diferença é grande.

O que esperamos é que o aluno saiba que essas questões são densas, que ele não pode ser leviano ao tratá-las. 0 que se espera de um aluno que faz esses cursos é que ele tenha capacidade de entender quais foram os principais problemas discutidos pelos textos. Pressupor que, como o aluno já tem tantos afazeres, é melhor que o professor digira o conteúdo do curso, é um erro pior do que sugerir uma bibliografia imensa. 0 aluno precisa saber que a leitura é fundamental.

A nossa experiência é que as disciplinas de teoria são formativas. São cursos quase basilares para continuação do curso, seja em qual área for, mesmo que seja em Antropologia, digamos. 0 aluno precisa de alguma maneira saber que certos termos políticos são conceitos produzidos historicamente, que "democracia" é um conceito, que "governo" é um conceito. Ele não pode sair do curso de Ciências Sociais sem saber isso. Eu acho que são nesses cursos que essas questões são tratadas.

Primeiros Estudos: Sobre a questão de uma autorreflexão sobre a possibilidade de mudanças dos cursos que o Departamento de Ciência Politica oferece, e tratando também da questão dos cursos de Teoria: há muitos alunos que têm dificuldades inclusive em ler os textos, em como ler esses textos etc. Você está coordenando agora um projeto no "Ensinar com Pesquisa", quer visa diminuir essas dificuldades. É possível agregar esse projeto ao Departamento de forma geral e quais são as possibilidades de mudanças futuras? 
EUNICE OSTRENSKY: Nós contamos atualmente com muitas bolsas que são da própria USP. Acho que os professores devem aproveitar essas oportunidades. Estou fazendo algo experimental [no projeto "Ensinar com Pesquisa"] que diz respeito a ensinar a ler, escrever um texto. Textos teóricos, como eu disse, exigem atenção redobrada e paciência. A meu ver, um projeto semelhante - seja pensado por curso ou por área de conhecimento - deveria ser institucionalizado, para não dependerem da boa vontade de professores interessados em levar isso adiante. No caso do meu projeto, especificamente, o objetivo principal é melhorar a formação dessas quatro alunas contempladas com bolsa pelo programa. Em segundo lugar, o projeto visa ao atendimento dos alunos de primeiro ano, em particular, na leitura e redação de textos acadêmicos. Por último, as bolsistas estão começando a ter uma experiência de docência também. Então, para elas é bom e para os alunos é bom. Infelizmente, os alunos não comparecem. Embora as alunas beneficiadas pelo projeto estejam disponíveis toda a semana, elaborando textos, fazendo resenhas, os alunos da graduação não aparecem.

Primeiros Estudos: Você poderia deixar um pouco mais claro como é esse projeto do "Ensinar com Pesquisa"?

Eunice OSTRENSKY: Eu observei o programa da disciplina Política I e o escolhi para trabalharmos porque percebo que os alunos recém ingressos na faculdade não fazem a menor ideia de como o curso funciona. São várias questões, de como se estuda, do tipo de texto que será lido. Então pensei "esses alunos precisam aprender a ler um texto, antes de qualquer coisa”... Aliás! Temos outro problema sério aqui na faculdade que é o plágio. Eu até escrevi um texto que iremos por no site da FFLCH e que terá um desdobramento. [Volta ao assunto anterior] Então, eu fiz um programa pensando em gradualmente ir aumentando a dificuldade. Ensinar a ler um texto, ensinar a discutir o texto, como discutir um texto com os alunos, depois passaremos para uma pequena análise desse texto, pedindo aos alunos que escrevam sobre os textos. Serão pequenos parágrafos a serem corrigidos pelas alunas beneficiadas pelo programa. Elas foram escolhidas basicamente pelo critério acadêmico. Elas são capazes, portanto, de ensinar e transmitir as experiências que tiveram. Aprenderão a escrever uma resenha, pegar textos de 
comentadores e analisar onde há convergência, onde há divergência. Selecionamos então uma sala para as reuniões e, na primeira experiência de encontro com os alunos, participaram trinta alunos. Na segunda vez, percebi que teríamos que ter uma sala maior que comportasse mais alunos, por que já eram quarenta alunos. Mas no terceiro encontro vieram somente dois alunos. Depois disso ninguém mais apareceu.

Primeiros Estudos: Por que isso?

EUNICE OSTRENSKY: Ou porque eles acham que vão conseguir entender sozinhos as regras de redação e leitura acadêmica, ou simplesmente porque acham que elas são desnecessárias. No semestre que vem [segundo semestre de 2011] ministrarei a matéria Política II novamente, ou seja, estarei com esses mesmos alunos [ingressantes de 2011]. Ano passado, quando fui professora de Política II, foi calamitoso. São alunos apáticos, não conseguem nem formular dúvidas. Nós sabemos que o aluno tem dificuldade em formular dúvidas para o professor, pois bem, então formule para o monitor, um aluno que é seu colega. Estão perdidos. Trevas [risos]. De qualquer maneira, nós vamos continuar oferecendo esse projeto, porque para essas quatro alunas que estão participando do programa, a experiência é muito importante. Por isso, continuaremos com as atividades.

Primeiros Estudos: Acredito que eles devem fazer igual aos alunos de anos anteriores, aprendemos tropeçando.

EUNICE OSTRENSKY: Mas eu acho que poderia ter sido bem mais fácil. E talvez ainda haja lacunas que vocês não conseguiram suprir. É possível que isso fique mais aparente quando vocês tiverem no mestrado.

\section{Primeiros Estudos: $A$ iniciação científica ajuda, não?}

EuniCE OSTRENSKY: Ajuda. Mas muitos alunos não tiveram acesso a iniciação cientifica e chegarão ao último ano sem conseguir escrever um trabalho. Ando conversando com meus colegas dos outros departamentos, insistindo que esse 
projeto seja uma iniciativa da faculdade, algo institucionalizado, mesmo correndo o risco de não atingirmos a grande massa dos alunos.

Existe agora, também, o PEEG (Programa de Estimulo ao Ensino da Graduação) selecionando alunos para serem monitores de graduação nos semestres subsequentes. Outra nova chance. Atualmente há uma disposição em melhorar a graduação. Por outro lado, o aluno deve se encontrar no curso por conta própria. Ou seja, não sou uma defensora do paternalismo com o aluno, ele precisa aprender a "se virar". Precisamos deixar claro o que esperamos dele. 0 problema é que isso não está claro hoje. Nesse sentido, voltando a sua pergunta, não está claro o que os professores esperam dos alunos, o que dá margem a uma série de confusões.

Primeiros Estudos: Pensando na reformulação da grade, e da possível introdução de disciplinas como Redação, Redação Acadêmica.

EUNICE OSTRENSKY: O problema é introduzir mais disciplinas na grade. Não temos professores. Esse projeto seria algo mais fora da grade mesmo.

PRIMEIRos EstUdos: Fora da grade é um problema. Uma atividade que ocorra dois ou três dias por semana para além da carga horária do próprio curso e da carga de leitura fica bem difícil.

EuniCE OSTRENSKY: Seria o caso de talvez pensarmos a incorporação desse tipo de atividade às disciplinas, então?

\section{Primeiros Estudos: Pode ser.}

EuniCE OSTRENSKY: Vocês sabem que nas matérias introdutórias de Ciência Politica muitos alunos costumam ir embora na hora dos exercícios [propostos em sala de aula]. Principalmente os alunos da tarde. Os alunos da noite são mais sérios, eles tem um horário muito restrito de vivência na universidade. Pensarei para as próximas disciplinas como Política II, uma forma de implementar isso. Mas também, precisamos pensar que cada professor dá o seu curso. Não posso impor nada, mas posso conversar com professores que sabemos que têm mais disposição. 
PRIMEIRos Estudos: $O$ que você sugere para pessoas que querem seguir carreira acadêmica?

Eunice OSTRENSKY: [Risos] Em primeiro lugar, gostar de estudar. Se gostar mais ou menos, melhor não seguir carreira acadêmica porque é isso que você vai fazer, embora também haja o lado burocrático do ofício de professor: a Universidade está nas mãos dos professores. Há uma carga administrativa muito grande, mas é evidente que não é isso que deve motivar a busca pela carreira acadêmica. É essencial um interesse genuíno por estudar, curiosidade, e achar que o que esta fazendo é importante. Cada um deve ser capaz de justificar coerentemente o seu estudo num determinado assunto. Se a pessoa achar que a Universidade é um lugar no qual que ela terá liberdade para fazer exatamente o que ela quer, melhor não fazer, não existe isso.

Esse é um modelo de universidade que não existe mais. A própria USP não é mais assim. As pessoas que acham isso, daqui a pouco irão se aposentar. A Universidade é um local em que as pesquisas estão muito moldadas pelo que está acontecendo fora da Universidade, pelo que está acontecendo em outras Universidades, é um diálogo coletivo. Ninguém está sozinho aqui. É preciso saber que existe esse diálogo. É preciso, então, gostar de discutir, querer entender e saber também que a carreira acadêmica é uma carreira longa, exige uma serie de sacrifícios.

Os médicos reclamam da residência, a vida acadêmica demora muito mais! Estudamos mais, a nossa formação é muito mais densa do que a deles. Então, é preciso gostar de estudar e estar preparado para estudar durante muito tempo e para discutir com os colegas, saber o que é discutir uma pesquisa com os colegas, participar de grupos. Não é uma atividade em que as pessoas ficam estudando sozinhas em casa. Não, não é mais. E tem que se esforçar para ler em outras línguas. Caso não consiga ler em inglês, precisa se esforçar urgentemente para fazêlo e procurar se relacionar com pessoas que estão fazendo a mesma coisa que ela.

É preciso ingressar numa comunidade. Pesquisa se faz com outras pessoas. Recomendo que os alunos não busquem uma especialização precoce, e digo "especialização" no sentido de departamentos [referência aos três departamentos que compõe o curso de Ciências Sociais na USP, que são o de Antropologia, o de 
Ciência Política e o de Sociologia] mesmo, só ter experiência de disciplinas em tal departamento. Ao contrário, tentem adquirir uma formação que seja a mais ampla possível, porque isso será importante futuramente. É uma carreira muito longa, muito específica, muito exigente e que nunca terá uma boa remuneração [risos].

É preciso pensar também se vocês gostam de dar aula, mesmo que seja uma experiência difícil. No Brasil, ao contrário de países como França, México e Argentina, não existe o modelo de pesquisador acadêmico não docente. Aqui não, o pesquisador é docente também. A universidade não dissocia as duas coisas. Ou seja, de alguma maneira você tem que gostar de dar aula. E não poderá ser um bom pesquisador e um péssimo professor. Mas o inverso também é verdadeiro.

\section{Referências}

DARNTON, R. (1986). O grande massacre de gatos e outros episódios da história cultural francesa. Rio de Janeiro, Graal.

HobBes, T. (2001). Behemoth ou o longo parlamento (1679). Trad. Eunice Ostrensky. Belo Horizonte, UFMG.

LOCKE, J. (1998). Dois tratados sobre o governo. Trad. Julio Fischer, revisão técnica de Eunice Ostrensky. São Paulo, Martins Fontes.

Mill, J. S. (1999). A liberdade; utilitarismo. Trad. Eunice Ostrensky. São Paulo, Martins Fontes, 277 p. (Clássicos).

SKInNER, Q. (1981). Machiavelli. Oxford, Oxford University Press. das Letras.

(1996). As fundações do pensamento político moderno. São Paulo, Companhia

Smith, A. (1998). Teoria dos sentimentos morais. Trad. Lya Luft, revisão técnica de Eunice Ostrensky. São Paulo, Martins Fontes. 